\title{
ROLE OF REPETITIVE TRANSCRANIAL MAGNETIC STIMULATION IN TREATMENT OF COGNITIVE MANIFESTATIONS IN PARKINSON'S DISEASE
}

\author{
Taha Kamel Allosh, Mahmoud Haroun Elbalkemy, Nevine Medhat El Nahas, \\ Ali Soliman Ali Shalash, Tamer Hussen Emara \& Mohamed Ali Elshiekh*
}

Department Neurology and

Psychiatry, Faculty of Medicine, Ain

Shams University

Corresponding:

Mohamed Ali Elshiekh

Phone No.: (+2) 01007669675

Email:

elshiekhneuro@gmail.com.

Received: $2 / 3 / 2020$

Accepted: 30/3/2020

Online ISSN: 2735-3540

\begin{abstract}
Background: Parkinson's disease (PD) is the second common neurodegenerative disease and still the pharmacological treatment facing many problemsas motor complication and ineffectiveness of this treatment for most of the nonmotor symptoms. Non invasive brain stimulation (NIBS) as a new adjunctive method for treating these problems, repetitive transcranial magnetic stimulation one of NIBS techniques used in previous studies but with less consistent results concerning therapeutic effect on cognitivs symptoms of PD.
\end{abstract}

Aim of the work: determine whether HF-rTMS targeting $L t$ $D L P F C$ has beneficial effect on cognitive functions of PD patients, and if this effect present could last for longer periods after one month follow up.

Patients and Methods: this randomized single blind case-control clinical study included sixty patients with idiopathic parkinson's disease (PD) from neurology clinic of Ain Shams University hospitals in Cairo, in the period between December 2014 till December 2018. Subjects were classified according to UKPD Society Brain Bank Clinical Diagnostic Criteria into active and sham groups. Both groups are assessed before, immediately after completing 6 sessions of rTMS and 4 weeks after the last session.

Results: This study showed moderate significant improvement of cognitive symptoms in PD patients of active group compared to Sham group, this improvement limited to the immediately after rTMS phase not maintained in the follow up. Correlations of improvement were minimal between $T 2$ time scores of different scales.

Conclusion: HF rTMS applied over left DLPFC showed short term immediate improvement of cognitive functions of $P D$ patients but had no long lasting effects.

Keywords: Transcranial magnetic stimulation - Parkinson's disease - Dorsolateral prefrontal cortex.

\section{INTRODUCTION:}

Parkinson's disease (PD) is the second most common neurodegenerative disorder after Alzheimer's disease, affecting about $1 \%$ of adults aged over 60 years. The hallmarks of PD are its' motor symptoms: tremor, muscle rigidity, slowness of movement and postural instability. During the last decade in PD research, more focus than ever before has been given to the nonmotor symptoms of PD (including cognitive problems), as they entail a significant burden on independence in everyday activities and quality of life of the affected person, 
independent of the motor symptoms ${ }^{[1]}$.

Different mechanisms are involved according to the genes or environmental factors implicated in PD. In most patients, no genetic or environmental causes have been identified; these patients are referred to as having idiopathic PD (IPD $)^{[2]}$.

With clear evidence for concurrent abnormalities in the basal ganglia, thalamus and cortex, Parkinsonism is now recognized as a disease of a distributed brain network. Highly specific changes in neuronal activity, produced by dopamine loss in the putamen and other basal ganglia nuclei, or by the loss of dendritic spines on striatal output neurons, appear to severely disrupt the activity of neurons throughout the basal ganglia, thalamus and cortex, and may even lead to the aberrant activation of brain areas that are not part of the immediate basal gangliathalamocortical circuitry, eventually resulting in parkinsonism ${ }^{[3]}$.

The following 2 cellular pathologies are consistently found in patients with idiopathic PD: loss of dopaminergic neurons in the ventrolateral region of the substantia nigra (SN) and lewy pathologies (LP) in the brain stem. The marked dopaminergic cell loss at the time of diagnosis is the mainstay, whereas LP is highly variable in location and quantity (dependent on a number of less well-defined factors $)^{[4]}$.

The dorsolateral prefrontal cortex (DLPFC) is a region of interest because it could be implicated in both cognitive and motor symptoms of PD. However, studies in this brain region are limited and the extent of pathology is unclear. Abnormal functioning of the DLPFC has been implicated in PD patients in imaging studies ${ }^{[5]}$.

Prolonged treatment by dopaminergic medicine including levodopa, can cause motor complications. In addition, dopamine replacement therapy is essentially ineffective for most of the nonmotor symptoms ${ }^{[6]}$. Over the past decades, neuroscience researchers have benefited from technical advancements in non-invasive brain stimulation in humans. Transcranial magnetic stimulation (TMS) is one method used to deliver electrical stimuli through the scalp in conscious humans ${ }^{[7]}$.

Nearly 20 years ago repetitive transcranial magnetic stimulation (rTMS) was recommended for the treatment of Parkinson's disease. The pharmacokinetic effect of antiparkinsonian drugs and the physical intervention of rTMS deeply differ from each other. While the antiparkinsonian drugs have a faster and shorter effect, rTMS has a delayed effect after the stimulation. Furthermore, its effect is maintained for months ${ }^{[8]}$.

\section{AIM OF THE WORK:}

The aim of this study is to assess whether HF-rTMS targeting Lt DLPFC has significant effect on cognitive functions in PD patients, and if this effect continues in the follow up after four weeks.

\section{PATIENTS AND METHODS:}

\section{A. Study Population:}

Sixty patients with IPD All of them fulfilled the UK Brain Bank criteria for PD, were recruited after fulfilling the inclusion criteria and after approving to participate through a written informed consent.

Inclusion criteria:

- Age: subjects $\geq 40$ years old.

- $M M S E \geq 24$.

- Gender: both sexes

Exclusion criteria:

- Patients with secondary parkinsonism (eg: vascular, Neuroleptics ...etc) and parkinsonism plus syndromes (eg: Multiple system atrophy, progressive supranuclear palsy ...etc)

- Patients with dementia (MMSE < 24) 
- Secondary medical comorbidity that could affect outcome of the study

- Presence of contraindication for rTMS as history of seizures, presence of metallic devices, pace maker, head injuries or neurosurgical intervention with skull defect, pregnancy, history of migraine or frequent or severe headaches, history of hearing loss or The presence of cochlear implants, history of drug abuse or alcoholism.

\section{B. Study Procedure}

The patients were randomly assigned to either an actively treated group (n 29) or a sham-treated group (n 28).As 3 patients dropped out during sessions, patients were maintained on their medications without any modifications (on-state).

rTMS was performed over the left DLPFC with a Magstim rapid stimulator (Magventure, MagPro X100 with Mag Option) using a $70 \mathrm{~mm}$ figure-of-eight coil. The site of stimulation was $5 \mathrm{~cm}$ anterior in the parasaggital plane from the point of the optimal stimulation of right-hand muscles (primary motor area). The coil was held tangentially to the skull with the handle pointing occipital and parallel to the midline. 3000 pulses (40 pulses per train in 75 trains with intertrain interval 26 seconds) a day were applied using an intensity of $100 \%$ of resting motor threshold (RMT) with $10 \mathrm{~Hz}$ frequency for 6 days. Sham-rTMS was carried out in the same site with sham coil.

All subjects were subjected to baseline assessment before rTMS sessions (T1), immediately after 6 sessions (T2) and 4 weeks after the last session (T3).Evaluation consisted of Hoehn and Yahr scale $(\mathrm{H} \& \mathrm{Y})^{[9]}$. For cognitive assessment Wiconsin card sorting test (WCST), trail making test (TMTA \& TMTB) ${ }^{[10]}$, Digit span (DS), Frontal assessment battery (FAB) ${ }^{[11]}$,Clock draw test (CDT) for visuospatial function $^{[12]}$.

\section{Statistical analysis}

All data recording and statistical analysis were done using the 'Statistical Package for Social Science (SPSS) version 23. Testing normality distribution by Kolmogorov-Smirnovtest which showed that Age, AOO, DOI data follow the normal distribution so for these data parametric tests used (T-test and rmanova) otherwise other tests do not follow normal distribution so non parametric test used (Mann-Witney U test and Friedman test). P-value is used to indicate the level of significance, $\mathrm{P}>0.05$ : Insignificant, $\quad \mathrm{P}<0.05$ : Significant and $\mathrm{P}<0.01$ : Highly significant.

\section{RESULTS:}

There were no significant differences between the baseline characteristics of actively and sham-treated groups (Tables 1 and 2). 57 of the enrolled patients finished the study protocol. As 3 patients dropped out during sessions, patients were maintained on their medications without any modifications (on-state). No side-effects occurred in the treated group.

Table (1): Demographics of all patients in active and sham groups

\begin{tabular}{|c|c|c|c|c|c|}
\hline & & \multicolumn{2}{|c|}{ Groups } & \multirow{2}{*}{\multicolumn{2}{|c|}{$\begin{array}{c}\text { T-Test / } \\
\text { Chi-Square * }\end{array}$}} \\
\hline & & \multirow{2}{*}{$\begin{array}{c}\text { active group } \\
\left(\mathrm{N}=\mathrm{rq}^{q}\right)\end{array}$} & \multirow{2}{*}{$\frac{\text { sham group }}{(\mathrm{N}=\mathrm{r} \wedge)}$} & & \\
\hline & & & & $\mathrm{T} / \mathrm{X}^{2^{*}}$ & P-value \\
\hline \multirow[b]{2}{*}{ Sex } & Male & $19\left(6^{\circ} .5 \%\right)$ & $2 \cdot(71.4 \%)$ & \multirow[t]{2}{*}{$0 . \Upsilon r \cdot *$} & \multirow[t]{2}{*}{0.74} \\
\hline & Female & $1 \cdot(34.5 \%)$ & $\wedge(28.6 \%)$ & & \\
\hline \multicolumn{2}{|c|}{ Age Mean(SD) } & $57.35(11.59)$ & $53.32(9.86)$ & 1.409 & 0.164 \\
\hline \multicolumn{2}{|c|}{ Age of onset Mean(SD) } & $52.55(11.35)$ & $47.82(10.15)$ & 1.657 & 0.103 \\
\hline \multicolumn{2}{|c|}{ Duration of illness by years Mean (SD) } & $5.14(2.52)$ & $5.86(2.95)$ & -0.991 & 0.326 \\
\hline
\end{tabular}


Table (2): comparison between baseline scales of all patients in active and sham.

\begin{tabular}{|c|c|c|c|c|c|c|c|c|c|c|}
\hline \multirow[t]{2}{*}{ Scales } & \multicolumn{4}{|c|}{ Active } & \multicolumn{4}{|c|}{ Sham } & \multicolumn{2}{|c|}{$\begin{array}{c}\text { T-test* / Mann- } \\
\text { Whitney U }\end{array}$} \\
\hline & Mean(SD) & median & $\mathrm{IC}$ & & Mean(SD) & median & & $2 \mathrm{R}$ & $\mathrm{T} / \mathrm{Z}$ & $\mathrm{P}$ \\
\hline H\&Y_T1_off & $3.52(0.89)$ & 4 & 3 & 4 & $3.27(0.70)$ & 3 & 3 & 4 & -1.046 & 0.295 \\
\hline H\&Y_T1_on & $2.59(0.79)$ & 2.5 & 2 & 3 & $2.23(0.73)$ & 2 & 1.5 & 3 & -1.586 & 0.113 \\
\hline WCST CC_T1_on & $42.92(29.03)$ & 50 & 0 & 66.6 & $43.61(29.62)$ & 50 & 0 & 66.6 & -0.284 & 0.776 \\
\hline WCST TE_T1_on & $71.07(20.04)$ & 74 & 55.5 & 88 & $60.04(22.10)$ & 61.5 & 41 & 81 & -1.885 & 0.059 \\
\hline WCST PE_T1_on & $42.55(32.15)$ & 44 & 6 & 71 & $31.86(25.20)$ & 32.5 & 5 & 46.25 & -1.247 & 0.213 \\
\hline WCST NPE_T1_on & $28.31(30.93)$ & 16 & 6.5 & 44 & $28.18(30.41)$ & 13 & 2.25 & 43 & -0.144 & 0.886 \\
\hline FAB_T1_on & $14.62(2.16)$ & 14 & 13 & 16 & $15.39(2.42)$ & 16 & 15 & 17 & -1.592 & 0.111 \\
\hline DS_T1_on & $9.34(2.50)$ & 9 & 7.5 & 12 & $10.82(3.17)$ & 11.5 & 9 & 14 & -2.096 & 0.056 \\
\hline CDT_T1_on & $8.10(1.23)$ & 8 & 7 & 9 & $8.00(0.77)$ & 8 & 7 & 9 & -0.739 & 0.460 \\
\hline TMTA_T1_on & $2.62(1.18)$ & 3 & 1 & 4 & $2.21(0.96)$ & 2 & 1 & 3 & -1.463 & 0.144 \\
\hline TMTB_T1_on & $2.66(1.17)$ & 3 & 1.5 & 4 & $2.71(1.01)$ & 3 & 2 & 3.75 & -0.099 & 0.921 \\
\hline BDI_T1_on & $3.24(0.69)$ & 3 & 3 & 4 & $3.00(0.82)$ & 3 & 2 & 4 & -1.138 & 0.255 \\
\hline ESS_T1_on & $1.72(0.96)$ & 1 & 1 & 3 & $2.04(0.74)$ & 2 & 1.25 & 3 & -1.641 & 0.101 \\
\hline FSS_T1_on & $40.93(10.17)$ & 43 & 35 & 47 & $37.14(14.65)$ & 41.5 & 21.5 & 50 & -0.727 & 0.467 \\
\hline
\end{tabular}

*statistically significant

\section{Comparative study results}

In the actively treated group, WCST PE improved with $p=0.001$ (16.78 points, 39\% at T2) (27.82 point, $65 \%$ at T3). WCST NPE showed deterioration with $p=0.025$ (25.34 points, 95\% at T3) Regarding WCST CC and WCST TE showed No statistically significant change. FAB improved $(p<0.001)$ with positive post hoc result at T2 and T3 $(p<0.001$ and $p=0.043)$. CDT improved $(\mathrm{p}<0.001)$, with positive post hoc result at T2 $(p=0.029)$. TMTA, TMTB and DS showed improvement $(p=0.009,0.035$ and 0.004 respectively), but with negative post hoc results (Table 3, 4) (Diag1-5).

In the sham-treated group, WCST PE improvement $(p<0.001)$, with positive post hoc result at T2 $(p=0.004)$. WCST NPE showed deterioration $(p=0.021)$, with positive post hoc result at T2 $(p=0.031)$. FAB and CDT showed improvement ( $p=0.020, \quad p=0.001$ respectively), with negative post hoc result. Regarding WCST CC and WCST TE, TMTA, TMTB and DS showed No statistically significant change.

Table (3): Comparison between active and sham groups regarding cognitive function across 3 times

\begin{tabular}{|c|c|c|c|c|c|c|c|c|}
\hline & \multicolumn{3}{|c|}{ active } & \multirow[b]{2}{*}{$\mathrm{p}$} & \multicolumn{3}{|c|}{ sham } & \multirow{2}{*}{$\mathrm{p}$} \\
\hline & T1 & $\mathrm{T} 2$ & T3 & & $\mathrm{T} 1$ & $\mathrm{~T} 2$ & T3 & \\
\hline $\mathrm{H} \& \mathrm{Y}$ & $2.63(0.80)$ & $2.43(0.95)$ & $2.52(0.94)$ & $0.001 *$ & $2.27(0.74)$ & $2.25(0.74)$ & $2.29(.72)$ & 0.223 \\
\hline WCST CC & $44.25(28.86)$ & $42.12(32.81)$ & $34.34(35.39)$ & 0.637 & $44.40(29.15)$ & $43.45(31.39)$ & $37.69(32.23)$ & 0.779 \\
\hline WCST TE & $69.26(19.60)$ & $63.30(22.72)$ & $66.78(27.19)$ & 0.282 & $59.77(21.26)$ & $58.73(21.35)$ & $57.08(22.39)$ & 0.202 \\
\hline WCST PE & $42.67(31.36)$ & $25.89(27.00)$ & $14.85(22.24)$ & $0.001^{*}$ & $33.04(25.37)$ & $22.19(25.39)$ & $25.92(25.13)$ & $<0.001^{*}$ \\
\hline WCST NPE & $26.59(28.88)$ & $37.41(31.77)$ & $51.93(37.16)$ & $0.025^{*}$ & $26.73(28.14)$ & $36.54(27.02)$ & $31.15(30.06)$ & $0.021 *$ \\
\hline FAB & $14.70(2.22)$ & $16.60(1.53)$ & $15.63(2.15)$ & $<0.001^{*}$ & $15.42(2.45)$ & $15.65(2.46)$ & $15.73(2.44)$ & $0.020 *$ \\
\hline CDT & $8.03(1.26)$ & $8.59(1.12)$ & $8.44(1.12)$ & $<0.001^{*}$ & $8.00(0.80)$ & $8.19(0.80)$ & $8.34(0.94)$ & $0.001 *$ \\
\hline TMTA & $2.56(1.19)$ & $2.19(1.04)$ & $2.48(1.28)$ & $0.009^{*}$ & $2.19(0.90)$ & $2.08(0.89)$ & $2.08(0.89)$ & 0.276 \\
\hline TMTB & $2.63(1.18)$ & $2.37(1.08)$ & $2.52(1.19)$ & $0.035^{*}$ & $2.77(0.99)$ & $2.62(0.98)$ & $2.73(0.96)$ & 0.074 \\
\hline DS & $9.19(2.51)$ & $10.04(2.71)$ & $9.44(2.76)$ & $0.004^{*}$ & $10.85(3.15)$ & $11.12(2.90)$ & $11.04(2.93)$ & 0.412 \\
\hline
\end{tabular}

*statistically significant; H\&Y scale: Hoehn and Yahr staging of Parkinson's disease severity WCST CC: Wisconsin card sorting test completed category; WCST TE: Wisconsin card sorting test total errors; WCST PE: Wisconsin card sorting test preservative errors; WCST NPE: Wisconsin card sorting test Non preservative errors; CDT: clock draw test; FAB: frontal assessment battery; DS: digit span; TMTA: Trail making test part A; TMTB: Trail making test part B. 
Role Of Repetitive Transcranial Magnetic Stimulation In Treatment Of Cognitive Manifestations.

Table (4): Post Hoc Comparison of Cognitive scales in sham group across 3 time points

\begin{tabular}{|c|c|c|c|c|c|c|c|c|c|c|}
\hline \multirow{3}{*}{ WCST PE T2-T1 } & \multicolumn{4}{|c|}{ active } & \multirow{3}{*}{$\begin{array}{c}\mathrm{p} \\
0.088\end{array}$} & \multicolumn{4}{|c|}{ sham } & \multirow{3}{*}{$\begin{array}{c}\mathrm{p} \\
0.004^{*}\end{array}$} \\
\hline & \multirow{2}{*}{$\begin{array}{c}\text { Mean (SD) } \\
-16.14(28.69)\end{array}$} & \multirow{2}{*}{$\begin{array}{c}\text { Media } \\
n \\
-8\end{array}$} & \multicolumn{2}{|c|}{ IQR } & & \multirow{2}{*}{$\begin{array}{c}\text { Mean (SD) } \\
-12.86(15.31)\end{array}$} & \multirow{2}{*}{$\begin{array}{c}\text { Media } \\
\mathrm{n} \\
-7\end{array}$} & \multicolumn{2}{|c|}{ IQR } & \\
\hline & & & $\begin{array}{c}- \\
27.5 \\
\end{array}$ & 0 & & & & -27.75 & 0 & \\
\hline WCST PE T3-T1 & $-27.82(31.09)$ & -16 & -52 & 0 & $0.003^{*}$ & $-6.96(11.52)$ & -1 & -6.25 & 0 & 0.080 \\
\hline $\begin{array}{c}\text { WCST NPE T2- } \\
\text { T1 }\end{array}$ & $10.35(32.54)$ & 5 & -1.5 & 24 & 0.267 & $11.46(17.99)$ & 6 & -1 & $\begin{array}{c}28 . \\
5\end{array}$ & $0.031 *$ \\
\hline $\begin{array}{c}\text { WCST NPE T3- } \\
\text { T1 }\end{array}$ & 25.33(39.94) & 9 & -1 & 59 & $0.029 *$ & $5.42(14.44)$ & 0 & -1.25 & $\begin{array}{c}8.2 \\
5\end{array}$ & 1.000 \\
\hline FAB T2-T1 & $1.86(1.51)$ & 2 & 0.5 & 3 & $<0.001^{*}$ & $0.21(0.50)$ & 0 & 0 & $\begin{array}{c}0.7 \\
5\end{array}$ & 0.716 \\
\hline FAB T3-T1 & $0.93(1.17)$ & 1 & 0 & 2 & $0.043 *$ & $0.27(0.60)$ & 0 & 0 & 1 & 0.381 \\
\hline CDT T2-T1 & $0.52(0.63)$ & 0 & 0 & 1 & $0.029 *$ & $0.18(0.39)$ & 0 & 0 & 0 & 0.895 \\
\hline CDT T3-T1 & $0.41(0.75)$ & 0 & 0 & 1 & 0.267 & $0.35(0.49)$ & 0 & 0 & 1 & 0.184 \\
\hline
\end{tabular}

*statistically significant; IQR: interquartile range

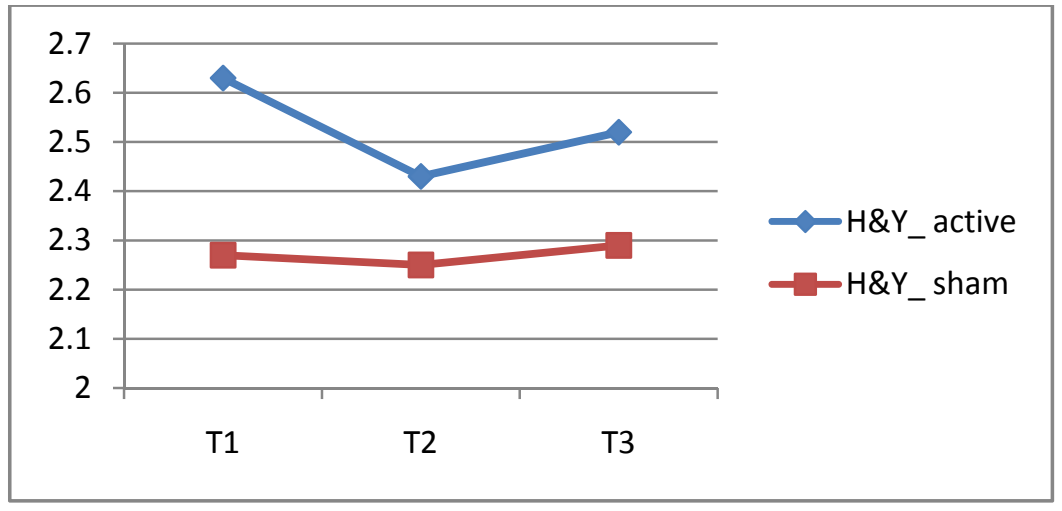

Diagram (1): Means of H\&Y scale in active group and sham group across three time points

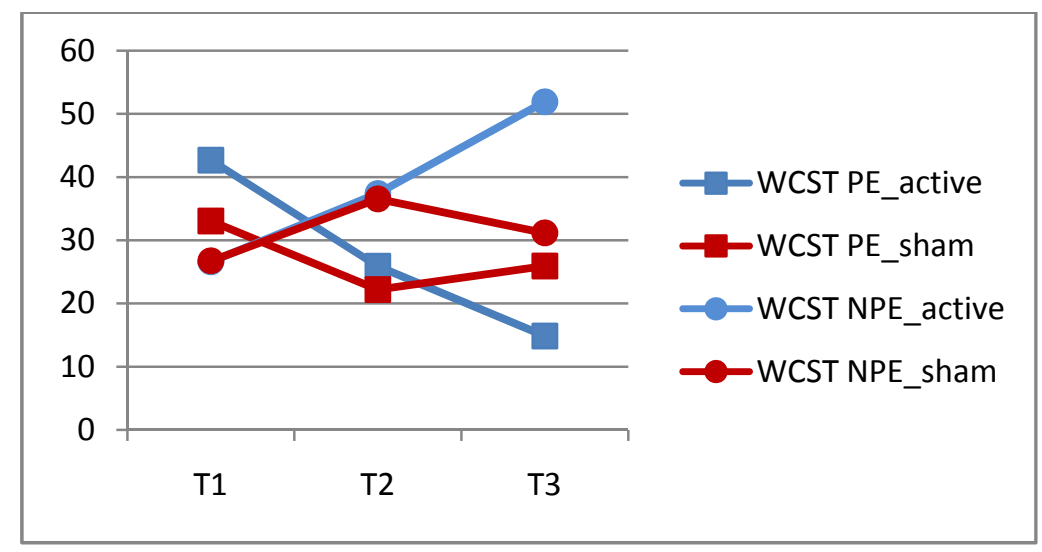

Diagram (2): Means of WCST PE and WCST NPE in active group and sham group across three time points 
Taha Kamel Allosh, et al.,

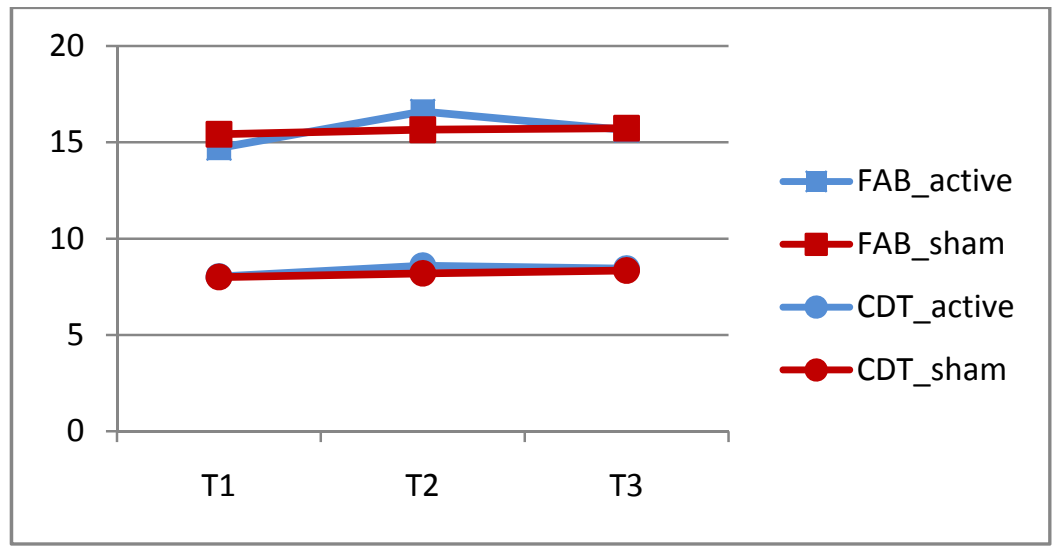

Diagram (3): Means of FAB and CDT in active group and sham group across three time points

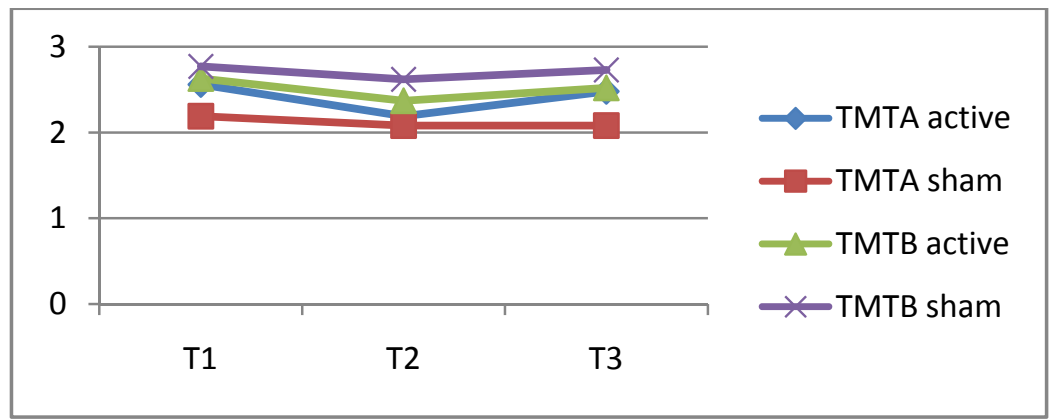

Diagram (4): Means of TMTA and TMTB in active group and sham group across three time points

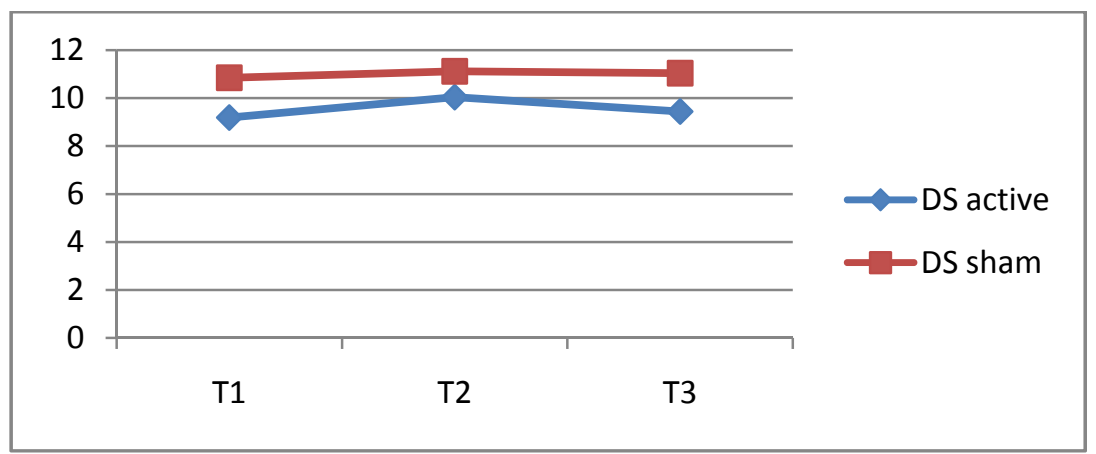

Diagram (5): Means of DS in active group and sham group across three time points

\section{Correlation study results:}

Demographic data statistical correlation study of baseline cognitive scales showed negative significant correlation of DOI with WCST CC, FAB and CDT and positive with TMTA and TMTB; there was negative correlation of AOO with DS; there was positive significant correlation between age of patients with TMTB and negative with DS otherwise no other significant correlation (Table 5) (Diag 6-9). 
Role Of Repetitive Transcranial Magnetic Stimulation In Treatment Of Cognitive Manifestations.

Table (5): Correlation between baseline WCST cognitive scales and demographic data:

\begin{tabular}{|c|c|c|c|c|c|c|}
\hline & \multicolumn{2}{|c|}{ Age } & \multicolumn{2}{c|}{ AOO } & \multicolumn{2}{c|}{ DOI } \\
\cline { 2 - 7 } & rho & Sig & rho & Sig & rho & Sig \\
\hline H\&Y_T1 off & 0.317 & $0.016^{*}$ & 0.271 & $0.041^{*}$ & 0.290 & $0.029^{*}$ \\
\hline H\&Y_T1 on & 0.223 & 0.096 & 0.228 & 0.088 & 0.153 & 0.255 \\
\hline WCST-CC_T1 & -0.197 & 0.143 & -0.199 & 0.138 & -0.277 & $0.037^{*}$ \\
\hline WCST-TE_T1 & 0.241 & 0.071 & 0.250 & 0.060 & 0.119 & 0.377 \\
\hline WCST-PE_T1 & 0.02 & 0.883 & -0.009 & 0.944 & -0.147 & 0.275 \\
\hline WCST-NPE_T1 & 0.060 & 0.657 & 0.078 & 0.564 & 0.169 & 0.208 \\
\hline FAB_T1 & -0.227 & 0.089 & -0.182 & 0.175 & -0.286 & $0.031^{*}$ \\
\hline TMT A_T1 & 0.206 & 0.124 & 0.133 & 0.325 & 0.353 & $0.007^{*}$ \\
\hline TMT B_T1 & 0.261 & $0.050^{*}$ & 0.199 & 0.138 & 0.281 & $0.034^{*}$ \\
\hline DS_T1 & -0.308 & $0.020^{*}$ & -0.340 & $0.010^{*}$ & -0.125 & 0.352 \\
\hline CDT_T1 & -0.233 & 0.082 & -0.175 & 0.192 & -0.318 & $0.016^{*}$ \\
\hline
\end{tabular}

*statistically significant; rho: Spearman correlation

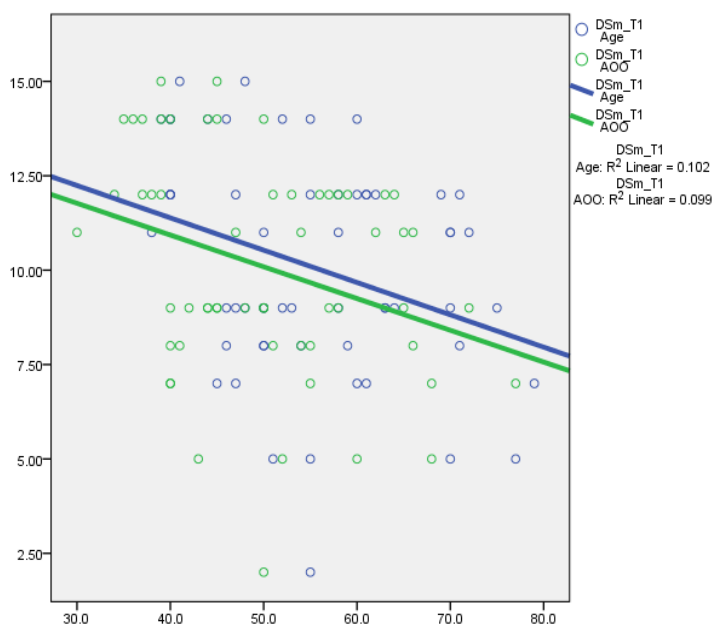

Diagram (6): Correlation of DS with age and AOO

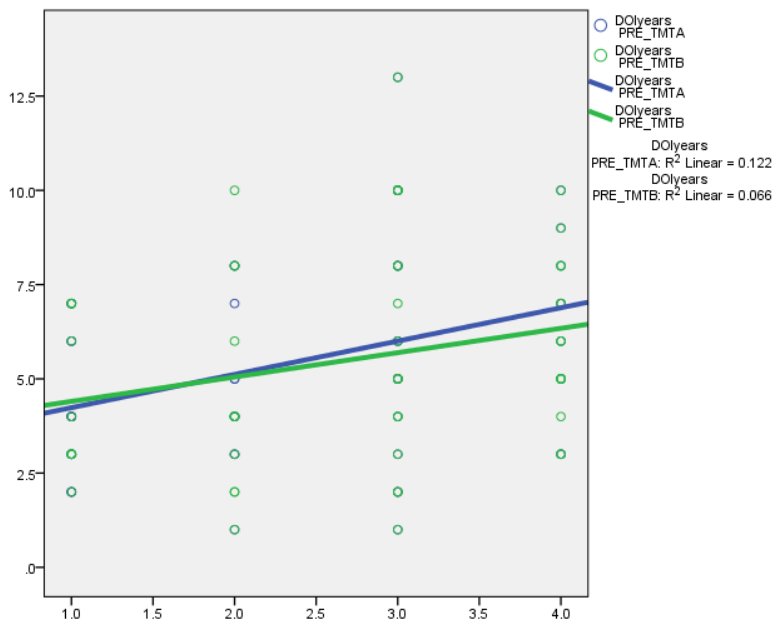

Diagram (8): Correlation of DOI with baseline TMTA and TMTB

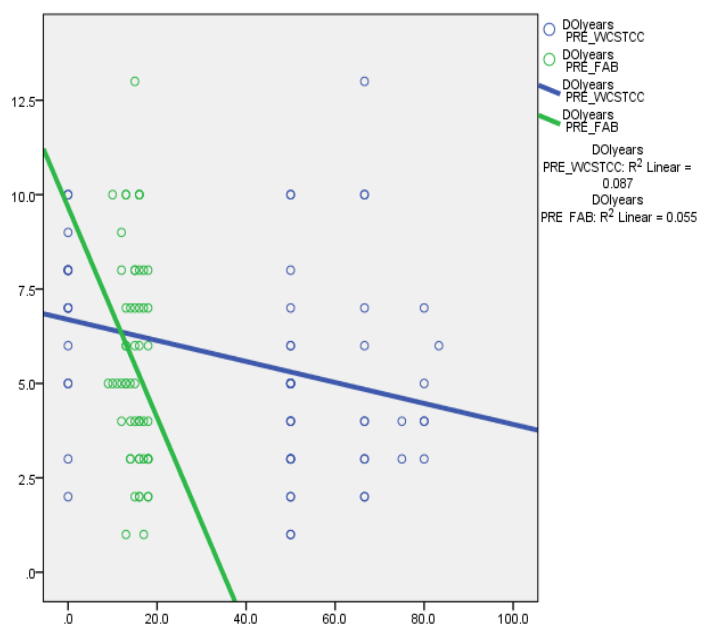

Diagram (7): Correlation of DOI with baseline WCST CC and FAB

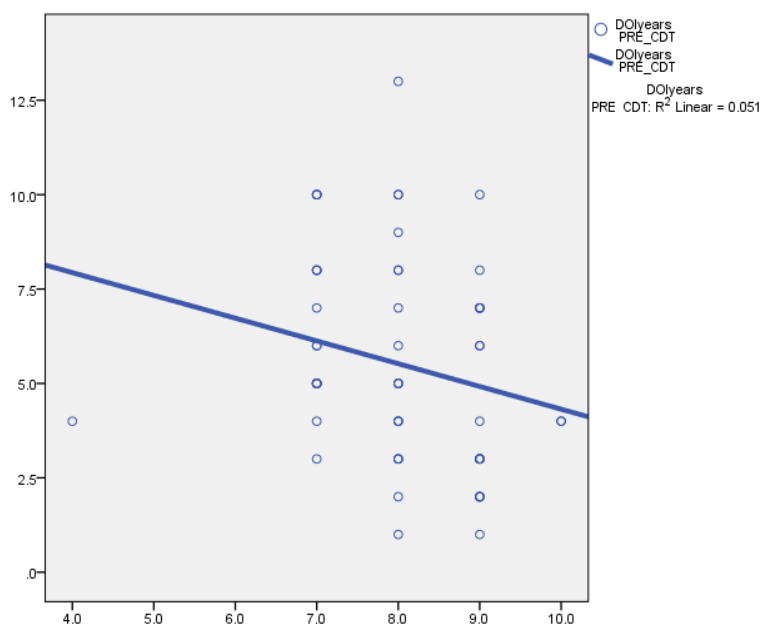

Diagram (9): Correlation of DOI with baseline CDT. 


\section{DISCUSSION}

Prolonged treatment by dopaminergic medicine including levodopa, can cause motor complications. In addition, dopamine replacement therapy is essentially ineffective for most of the nonmotor symptoms. So various pharmacological and non-pharmacological therapies have been tried, some of which are successful, such as the deep brain stimulation. Noninvasive brain stimulation including repetitive transcranial magnetic stimulation (rTMS) can also be a nonpharmacological therapeutic option for Parkinson's disease (PD) and could well is an important adjunctive therapy supporting dopaminergic medication ${ }^{[6]}$.

Despite numerous publications, there is no full agreement about which frequency for stimulation is the most favorable improving the behavior of PD patients. The issue of stimulation frequency was further investigated in meta-analysis, where studies using HF and LF rTMS were analyzed separately. In total 275 patients were included from 10 studies, whose baseline Hoehn and Yahr stages were between 1 and 4. The result showed efficacy of HF rTMS: the pooled mean effect size $(95 \% \mathrm{CI})$ was $0.58(0.27,0.90)$, in favor of rTMS, whereas effects of LF rTMS were too variable to draw any firmconclusion ${ }^{[13]}$.

There is agreement on having the period of stimulation last for 6-10 days. One session of stimulation was not effective in PD also a shorter period (4 days) had no effect in $\mathrm{PD}^{[14]}$.

Repetitive transcranial magnetic stimulation (rTMS) of the dorsolateral prefrontal cortex (DLPFC) has in many instances been proven to exert antidepressant-like effects superior to placebo and equivalent to standard psychopharmacological treatment. In regards PD-related cognitive impairment, the results from rTMS studies are mixed and so far lacking of highquality RCTs. but Due to the similar neuroanatomy and neurophysiology of executive and affective control processes, rTMS to the DLPFC may be able to address multiple issues simultaneously ${ }^{[15]}$.

In the current study the efficacy of HFrTMS over Lt DLPFC (F3) on cognitive manifestations of idiopathic parkinson's disease was assessed. Sixty patients randomized into case group (received 6 consecutive active rTMS sessions) and control group (received 6 consecutive sham rTMS sessions) while both groups were on the medical treatment levodopa supplementation (ON_state). Our hypothesis suggesting there is significant change on cognitive manifestation because many basic neuroscientific data confirm on the role of DLPFC in cognitive functions.

Patients not assessed in OFF_state as many patients became severely impaired while they were in (OFF_state), with great difficulty in performing our assessment scales. In addition the aftereffect of brain stimulation is influenced by simultaneous administration of central nervous system acting drugs ${ }^{[16,17]}$.

The demographics and clinical characteristics of studied sample showed that both groups (case and control) are homogenous and there was no difference in baseline scores of all assessment scales among them. We also noticed that male patients are more common than female ones (1.9:1 in case group, 2.5:1 in control group) and this ratio nearly equal the known male: female ratio of $\mathrm{PD}=2: 1$ published by ${ }^{[18,19}$, 20].

Cognitive functions showed improvement in attention visual scanning, speed of eye-hand coordination which assessed by improving DS and TMTA scores $(8.5 \%$ and $13 \%$ ) in active group only without time discrimination (negative post hoc), executive functions also improved especially cognitive flexibility (lexical fluency and shifting set), inhibitory control, programming, sensitivity 
to interference which assessed by improving FAB score $(11.4 \%)$ in T2 and T3, WCST PE score $(65 \%)$ in $\mathrm{T} 3$ and TMTB score $(9.8 \%)$ without time discrimination, all favoring active group. Visuospacial functions which assessed by CDT showed improvement $(6.5 \%)$ in $\mathrm{T} 2$ favoring active group.

Maintained attention which assessed by WCST NPE showed statistically significant change in form of deterioration at $\mathrm{T} 3$ in active group (25.34 points, 95\%, $\mathrm{P}=0.009$ ) and $\mathrm{T} 2$ in sham group (9.81 points, $36.7 \%$, $\mathrm{P}=0.021$ ).

The ambiguous result of WCST NPE could be explained as the conventional scoring of non-perseverative WCST errors does not discriminate between errors related to the efficient test of hypotheses during set shifting ('efficient errors'), and random failures to maintain set ('random errors'). This inherent confusion in the nonperseverative error score probably minimizes the relative importance of random errors in frontal lobe pathology. Nonperseverative errors also reduce the total amount of achieved categories, even though probably the brain mechanisms involved in this type of errors differ from those related to perseverative behavior ${ }^{[21]}$.

From previous studies which showed improvement of cognitive function is Boggio et al. study represented by WCST PE which showed statistically significant improvemet after 2 weeks assessment in comparison to baseline by about (4.9 points, $37.4 \%, P=0.004)$ and this improvement maintained and increased to about (7.3 points, $55.7 \%, P=0.003)^{[22]}$.

Also another study with improvement of cognitive function is Furukawa et al. showed that the number of achieved WCST categories increased significantly $(p<0.05)$. In addition, the numbers of preservative errors and the total errors decreased significantly $(\mathrm{p}<0.05)$, also TMT-B execution time significantly decreased after
rTMS $(\mathrm{p}<0.05)$ and maintained during the follow-up period ${ }^{[23]}$.

Another study Málly et al. showed Results of the TMT in PD $\leq 65$ yrs did not differ from those in controls below 65 years. However, the executive function of patients over 65 yrs $(\mathrm{N}=16)$ was significantly worse compared to controls $(\mathrm{N}=15)(\mathrm{C}$ : Trail $\mathrm{B}-\mathrm{A}$ : $50.0 \pm 25.1 \mathrm{~s}$, PD: Trail B-A $>65$ yrs: $76.0 \pm$ $45.1 \mathrm{~s} p<0.01)$. One month after rTMS treatment with $1 \mathrm{~Hz}$, an improvement was observed in the TMT compared with data at the baseline of treatment (PD: $48.70 \pm 21.4 \mathrm{~s}$ $\mathrm{p}<0.05)^{[8]}$.

Regarding severity which assessed by $\mathrm{H}$ $\& Y$ on there is statistically significant improvement across 3 time points in active group not in sham group $(\mathrm{P}=0.001)$ with negative post hoc results. On the contrary to the current study results most of previous studies didn't show improvement of H\&Y scale ${ }^{[24,25]}$. One study showed improvement by $17.3 \%$ but still insignificant $(\mathrm{P}=0.08)^{[26]}$.

In the current study the correlation between demographic data (age, AOO, DUI) with many cognitive functions (FAB, TMTA, TMTB, CDT) showed significant moderate correlation.

\section{Conclusion:}

The main conclusion of the current study could be based on that HF rTMS -as a method of non-invasive brain stimulation technique applied over left DLPFC- showed moderate significant improvement of cognitive symptoms in PD patients of active group compared to Sham group, this improvement limited to the immediately after rTMS phase not maintained in the follow up. There was a moderate degree correlation between demographic data (age, AOO, DUI) with many cognitive functions (FAB, TMTA, TMTB, CDT). Correlations of improvement were minimal between $\mathrm{T} 2$ time scores of different scales. 


\section{REFERENCES}

1. Randver, R. (2018). Repetitive transcranial magnetic stimulation of the dorsolateral prefrontal cortex to alleviate depression and cognitive impairment associated with Parkinson's disease: A review and clinical implications. Journal of the Neurological Sciences, 393, 88-99.

2. Lunati, A., Lesage, S., \& Brice, A.(2018). The genetic landscape of Parkinson's disease. Revue neurologique, 174, 628-643.

3. Galvan, A., \& Wichmann, T. (2008). Pathophysiology of parkinsonism. Clinical Neurophysiology, 119, 1459-1474.

4. Obeso, J. A., Stamelou, M., Goetz, C. G., Poewe, W., Lang, A. E., et al. (2017). Past, Present, and Future of Parkinson's disease: A Special Essay on the 200th Anniversary of the Shaking Palsy. Movement Disorders, 32(9), 1264-1310.

5. Lanoue, A. C. (2013). Neuropathology in the dorsolateral prefrontal cortex in Parkinson's disease. Thesis (Ph.D.)--Boston University.

6. Miocinovic, S., Somayajula, S., Chitnis, S., \&Vitek, J. L. (2013). History, applications, and mechanisms of deep brain stimulation. JAMA Neurology, 70, 163-171.

7. Klomjai, W., Katz, R., \&Lackmy-Valle'e, A. (2015). Basic principles of transcranial magnetic stimulation (TMS) and repetitive TMS (rTMS). Annals of Physical and Rehabilitation Medicine, 58, 208-213.

8. Málly, J., Geisz, N., \& Dinya, E. (2017). Follow up study: The influence of rTMS with high and low frequency stimulation on motor and executive function in Parkinson's disease. Brain Research Bulletin, 135, 98104.

9. Hughes, A. J., Daniel, S. E., Kilford, L., \& Lees, A. J. (1992). Accuracy of clinical diagnosis of idiopathic Parkinson's disease. A clinico-pathological study of 100 cases. Journal of neurology, neurosurgery and psychiatry, 55, 181-184.

10. Reitan, R. M. (1958). Validity of the Trail Making test as an indicator of organic brain damage. Percept Motor Skills, 8, 271276.
11. Dubois, B. and Litvan, I. (2000). The FAB: A frontal assessment battery at bedside. Neurology, 55(11), 1621- 1626.

12. Manos, P. J. (1998). 10-Point Clock Test Screens for Cognitive Impairment in Clinic and Hospital Settings. Psychiatric Times, Vol. XV, Issue 10.

13. Elahi, B., \& Chen, R. (2009). Effect of transcranial magnetic stimulation on Parkinson motor function - systematic review of controlled clinical trials. Movement Disorders, 24, 357-363.

14. Filipovic', S. R., Rothwell, J. C., \& Bhatia, K. (2010). Slow $(1 \mathrm{~Hz})$ repetitive transcranial magnetic stimulation (rTMS) induces a sustained change in cortical excitability in patients with Parkinson's disease. Clinical Neurophysiology, 121, 1129-1137.

15. Randver, R., Davel, K., \&Toomsoo, T. (2019). High-frequency repetitive transcranial magnetic stimulation to the left dorsolateral prefrontal cortex of patients with Parkinson's disease and treatmentresistant depression: a pilot study. Neurocase, 25, NOS. 3-4, 80-90.

16. Monte-Silva, K., Liebetanz, D., Grundey, J., Paulus, W.,\& Nitsch, M. A. (2010).Dosage-dependent non-linear effect of L-dopa on human motor cortex plasticity. Journal of Physiology, 588(18), 34153424.

17. Thirugnanasambandam, N., Grundey, J., Paulus, W., \&Nitsche, M. A. (2011). Dosedependent nonlinear effect of I-DOPA on paired associative stimulation-induced neuroplasticity in humans. Journal of Neuroscience, 31, 5294-5299.

18. Dluzen, D. E., \& McDermott, J. L. (2000): Gender differences in neurotoxicity of the nigrostriatal dopaminergic system: implications for Parkinson's disease. $J$ GendSpecif Med, 3(6): 36-42.

19. Van Den Eeden, S. K., Tanner, C. M., Bernstein, A. L., et al. (2003). Incidence of Parkinson's disease: variation by age, gender, and race/ethnicity. American Journal of Epidemiology, 157(11), 10151022.

20. Bordelon, Y., \&Fahn, S. (2006): Gender differences in movement disorders. In: Kaplan P, editor. Neurologic disease in women. Demos; New York. 
21. Barcelo', F., Knight R. T. (2002). Both random and perseverative errors underlie WCST deficits in prefrontal patients. Neuropsychologia, 40, 349-356.

22. Boggio, P. S., Fregni, F., Bermpohl, F., Mansur, C. G., Rosa, M., et al. (2005). Effect of repetitive TMS and fluoxetine on cognitive function in patients with Parkinson's disease and concurrent depression. Movement Disorders, 20(9), 1178-1184.

23. Furukawa, T., Izumi, S.-I., Toyokura, M., \&Masakado, Y. (2009). Effects of Lowfrequency Repetitive Transcranial Magnetic Stimulation in Parkinson's Disease. Tokai Journal of Experimental and Clinical Medicine, 34(3), 63-71.

24. Cardoso, E. F., Fregni, F., Martins, M. F., Boggio, P. S., Luis, M., et al. (2008).rTMS treatment for depression in Parkinson's disease increases BOLD responses in the left prefrontal cortex. International Journal of Neuropsychopharmacology, 11(2), 173183.

25. Pal, E., Nagy, F., Aschermann, Z., Balazs, E., \& Kovacs, N. (2010). The impact of left prefrontal repetitive transcranial magnetic stimulation on depression in Parkinson's disease: a randomized, double-blind, placebo-controlled study. Movement Disorders, 25(14), 2311-2317.

26. Epstein, C. M., Evatt, M. L., Funk, A., et al. (2007). An open study of repetitive transcranial magnetic stimulation in treatment-resistant depression with Parkinson's disease. Clinical Neurophysiology, 118, 2189-2194. 
دور التحفيز المغناطيسي عبر الجمجمة في علاج الاضطرابات المعرفية عند مرضي الباركنسون طه كامل علوش، محمود هارون البلكيي،، نيفين ملحت النحاس، علي سليمان علي شئش، تامر حسين عمارة، محمد علي الثبن

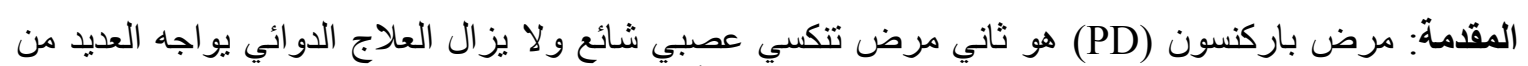

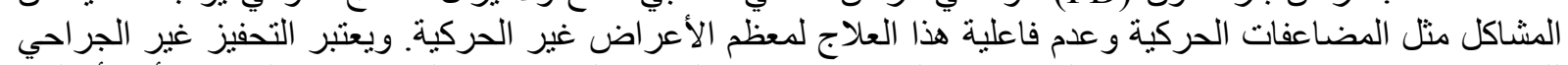

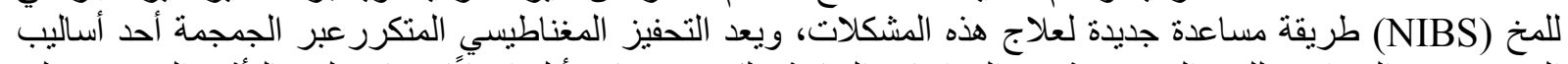

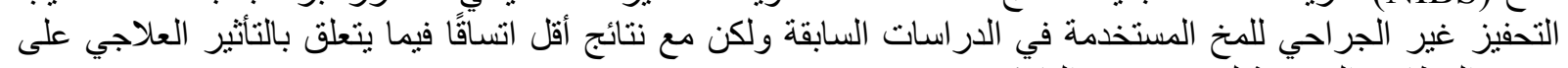

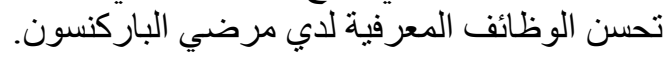

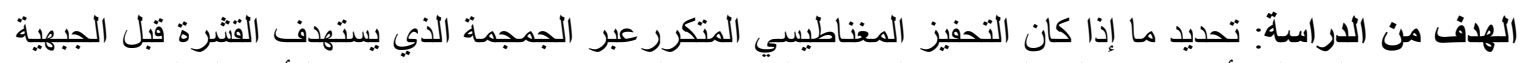

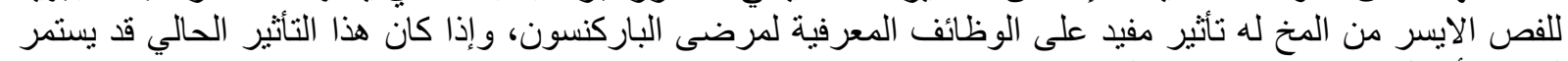

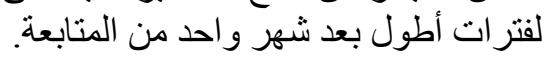

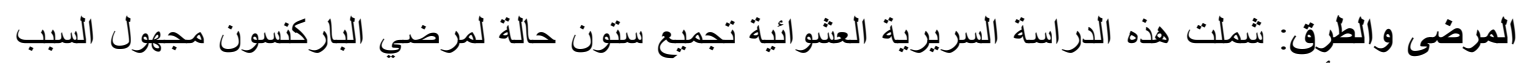

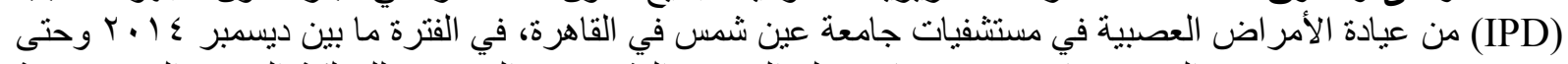

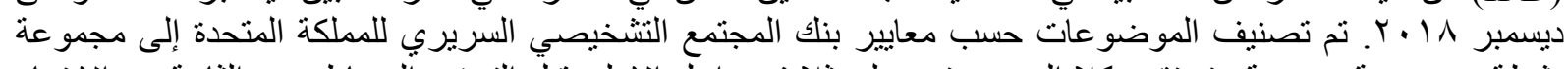

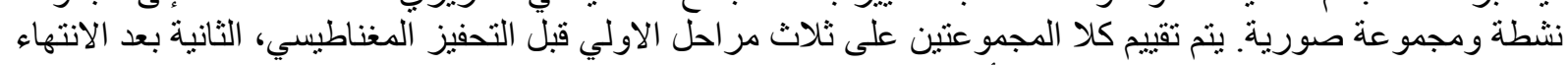

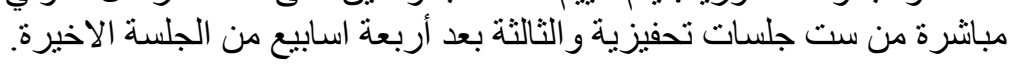

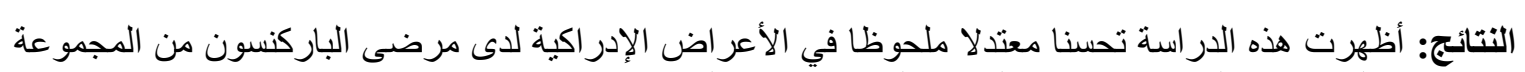

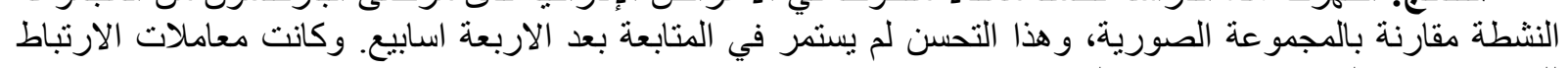
للتحسن بين مختلف الاختبار ات ضئيلة.

الخلاصة: التحفيز المغناطيسي المتكرر ذا التردد العالي علي منطقة القشرة المخية القبل جبهية اليسرى يحسن الوظائف المعرفية لمرضي الباركنسون علي المدي القريب دون نأثير أتئ طويلة المدي. 